\title{
ANALYSIS OF HYPERSALINE WATERS FROM COJOCNA BALNEARY RESORTS (ROMANIA) USING RAMAN SPECTROSCOPY TECHNIQUES
}

\author{
I. BREZESTEAN ${ }^{1}$, F. NEKVAPIL ${ }^{1}$, S. CINTA PINZARU ${ }^{1 *}$
}

\begin{abstract}
Analysis of hypersaline waters from Cojocna balneary resorts (Romania) using Raman spectroscopy techniques. Surface waters from hypersaline lakes of Cojocna Balneary Resort, Transylvania, Romania have been investigated in raw form, using Raman spectroscopy techniques. These lakes are usually exposed to high touristic influx mainly in summer months, due to their balneotherapeutic benefits. Therefore, chemical composition of waters and its variability is of high interest. Here we present spectroscopic characteristics of the lakes, obtained by Raman scattering techniques, probing several water samples collected in two consecutive years. Among the two lakes, Torok Lake showed 1.449 times higher sulfate concentration than the Great Lake in 2016 and 0.737 in 2017 respectively, according to the calculated ratio of the Raman band of sulfate at $979 \mathrm{~cm}^{-1}$ relative to water band. Chemical changes associated with the presence of different plankton species and their density fluctuations were reflected in changes in resonance Raman scattering signal of carotenoids during Artemia salina crustaceans blooming population in August, compared to July, in both years. Interestingly, the bloom appeared alternatively in two consecutive years and it is apparently correlated to lower sulfate level, as revealed by spectral data only. Raman data indicated the dynamic cycles in chemical composition of salt lakes. Such changes are certainly suitable for constant monitoring purpose of the balneotherapeutic salt water bodies via Raman spectroscopy. Both FT-Raman and dispersive Raman are suitable for this purpose. Fast analysis, without additional separation steps and chemicals consumption may provide information on the sulfate level and carotenoids. The results could be attractive for monitoring studies, or informative, for touristic purpose or aquaria hobby cultivars.
\end{abstract}

Keywords: hypersaline lakes, Raman spectroscopy, Cojocna balneary resort, carotenoids, sulfate.

\section{INTRODUCTION}

Hypersaline lakes from Cojocna Balneary Resort are traditionally valued for their curative properties for centuries. Currently, the modern saline resort is one of the most attractive balneary destination from Cluj County, Transylvania, Romania, (N: 46.748; E: 23.84, $604 \mathrm{~m}$ elevation). The two lakes, also known as Torok Lake and Great Lake respectively, are formed by dissolving salt of halite bedrock by underground springs in salt mine pits which were exploited from Daco Roman period to the Middle Age. Collapsed or cracked surface materials reached

\footnotetext{
${ }^{1}$ Biomolecular Physics Department, Babes-Bolyai University, Kogalniceanu 1, RO-400084 Cluj-Napoca, Romania, email: ioana brezestean@yahoo.com, nekifran@gmail.com

1* Corresponding author: Biomolecular Physics Department, Babes-Bolyai University, Kogalniceanu 1, RO-400084 Cluj-Napoca, Romania, email: simonapinzaru@gmail.com
} 
the unique hypersaline solution and generated complex, isolated and unique hypersaline ecosystems, with specific properties and dynamics (de Leeuw et al. 2012; Keresztes and Filipescu, 2005; Alexe et al. 2017). The geology of the region attributed Cojocna to a salt deposit of marine origin of Miocene age (de Leeuw et al. 2012; Keresztes and Filipescu, 2005). The former mining pit was slowly filled up with sediments at a speed of 1 meter per 10 years (Czellecz et al. 2016). Physico-chemical properties, depth profile, microbial diversity or mud analysis have been extensively reported (Alexe et al. 2017; Czellecz et al. 2016; Gheorghievici et al. 2015; Muntean 1996; Alinei et al. 2006; Keresztes et al. 2010, Keresztes et al 2012).

The reported salinity appeared variable, ranging between 31.4 and 101.01 $\mathrm{g} / 1$ in Torok Lale (Gheorghievici et al. 2015; Czellecz et al. 2016) and $31.2 \mathrm{~g} / \mathrm{l}$ in Great Lake, respectively (Czellecz et al. 2016), while the public information on site states $27 \% \mathrm{w} / \mathrm{v}$ total salt concentration. High salinity is favourable to host halophilic microorganisms of relatively low diversity, like green algae of genus Dunaliella (Keresztes et al. 2010; Oren 2014; Czellecz et al. 2016; Alexe et al 2017), Picocystis salinarum, and some diatoms that can grow in salt concentrations up to $150 \mathrm{~g} / 1$ (Roesler et al. 2002; Lewin et al. 2000; Clavero et al. 2000). According to Alexe et al. (2017) halophilic communities like green algae Dunaliella sp., brine shrimp Artemia sp., and members of Halobacteria class are dominant in the surface waters of the hypersaline surface lakes exceeding $10 \%$ salinity.

The lakes were subject of several studies regarding the diversity of microorganisms (Keresztes et al, 2010), or halophytes from the surrounding salty soil (Carpa et a. 2017). Green alga Dunaliella was first described by the Romanian botanist Emanuel C. Teodorescu (1905) and since then, impressive body of literature is devoted to it, as reviewed by Jehlicka and Oren (2013), Oren (2014) due to the important productivity of $\beta$-carotene under extreme saline conditions (Borowitzka et al. 2007, Borowitzka et al.,1981); or stress (Singh et al. 2016). In spite of the abundant literature, it is surprisingly scant information on this alga activity in its natural environment.

We introduced here for the first time a novel approach based on Raman techniques to probe the ability to extract chemical information from the raw, native environment of the hypersaline lakes, aiming to assess: i) their Raman scattering information; ii) the possibility to detect carotenoids without extraction, in the raw waters body, and iii) to probe the chemical changes correlations with the Raman spectroscopy signal of salt water, associated with the different behaviour of the two adjacent lakes regarding Artemia sp. bloom in summer.

Algal density is expected to influence the resonance Raman signal of the waters containing Dunaliella, via carotenoids signal. The potential of Resonance Raman (RR) spectroscopy to detect carotenoids biomarkers specific to living microorganisms from hypersaline environment like microbial mat, brine, biogeological sediments or even extraterrestrial materials has been extensively reported, as recently reviewed by (Jehlička and Oren 2013). They provided a review of the halophile research by Raman spectroscopy and summarized the main 
carotenoids band characteristic to halophile microorganisms containing scytonemin, phycobiliproteins, salinixanthin, bacterioruberin pigments and standard bacteriorhodopsin (Jehlička and Oren 2013).

Hypersaline lakes from balneotherapeutic tourist resorts are usually exposed to the increased touristic influx during summer and an informed concern about chemical characteristics of waters or their potential changes are of high interest. The salt lakes in Transylvania basin are also a popular source of Artemia harvesting for aquarium hobby cultivars. Moreover, scant studies using conventional bio-geological methods are not likely to be suitable for continuous monitoring purpose of the waters from balneary resorts.

Raman spectroscopy techniques and tools are able to provide a novel approach in this respect: the spectral signature arising from the vibrational frequencies of molecules is rich in chemical information. Potential changes in chemical composition of complex biosystems are reflected in specific spectral changes when proper Raman technique is employed.

Usually, blue or green lasers can excite resonantly the carotenoids species inside the plankton cells body, without extraction needed, thus providing a thousand fold increased intensity of carotenoid species from photosynthetic microorganisms present in water. To the best of our knowledge, Raman spectroscopy signature of the Cojocna Lakes waters was not reported.

\section{MATERIALS AND METHODS}

Sampling has been conducted by taking 11 water from each lake from 0.3 m depth (surface water) in early July 2016 and repeated in early August 2016. Similar sampling has been conducted in 2017. The small depth for sampling was chosen for optical reasons, given the poor transparency observed on site (objects immersed bellow $30 \mathrm{~cm}$ were not visible from the surface).

Fresh samples were transported in capped, sterile bottles to the laboratory, subsampled in multiple vials of $5 \mathrm{ml}$ capacity with screw cap and immediately investigated. Raman spectra have been recorded using three different setups. FTRaman system FRA106S integrated in Equinox 55 Bruker FT-IR spectrometer has been employed to record the spectra of the raw waters.

A quartz cuvette of $2 \mathrm{ml}$ was used to measure the bulk samples. A $\mathrm{Nd}$ :YAG laser operating at $1064 \mathrm{~nm}$ line was employed for excitation with an output power of $350 \mathrm{mw}$ and 400 scans were co-added.

Detection was achieved with a Ge detector operating at liquid nitrogen temperature. Opus 2.0 software was used for data acquisition and the spectral resolution was set to $4 \mathrm{~cm}^{-1}$. A DeltaNU compact, portable Raman system operating at $532 \mathrm{~nm}$ was employed for resonant excitation of carotenoids potentially present in the lakes waters. Glass cuvettes of $1 \mathrm{ml}$ were employed for sampling.

Data acquisition has been achieved using the NuSpec software. Five acquisition of $5 \mathrm{~s}$ each have been run to acquire each spectrum. A Renishaw InVia 
Reflex confocal Raman system has been employed for micro-Raman spectra acquisition from solid material resulted from $10 \mathrm{ul}$ water evaporation from each sample. A Cobolt diode pumped solid state (DPSS) air cooled laser operating at $532 \mathrm{~nm}$ has been employed for Raman excitation via a Leica research grade microscope with 100x (NA 0.9) long working distance objective. Detection was achieved with a RenCam CCD detector, $1024 \times 256$ pixels and spectral resolution was $0.5 \mathrm{~cm}^{-1}$.

Data acquisition has been achieved using the Wire 3.4 software. The laser power was set increasingly from 0.1 to $1 \mathrm{~mW}$ for the solid matter to avoid photobleaching and excessive fluorescence background in confocal Raman microscopy regime (Cinta Pinzaru et al, 2015). For the liquid samples $10 \mathrm{~mW}$ excitation power was employed using a liquid holder accessory at $90^{\circ}$ scattering collection

\section{RESULTS AND DISCUSSIONS}

Waters of the two lakes visually show different opacity and color ranging from blueish in July to dark green in fall August, reflecting the dynamic change in the plankton community composition during the summer months (Fig. 1). The brine shrimp blooming in August 2016 was observed in Lake 2 only, while in August 2017, in Lake 1, respectively.

\section{1. FT-Raman spectra of the surface waters from hypersaline lakes}

FT-Raman spectra of the water collected from the two lakes are showed in the Fig 2. Due to the high content of microorganisms, dissolved matter and suspensions, the signal showed strong noise superimposed on weak background, even for the NIR laser excitation.

The main bands form FT-Raman spectra are observed at $979 \mathrm{~cm}^{-1}$ and assigned to the symmetric stretching mode of sulfate (Ishizaka et al 2013), along with the typical Raman bands of water at about $1636 \mathrm{~cm}^{-1}$ (water bending mode) and the strong stretching modes around $3200 \mathrm{~cm}^{-1}$. Processed FT-Raman signal in the $800-3600 \mathrm{~cm}^{-1}$ of the waters from Lake 1 and 2 and named from now on Coj_1 and Coj_2, respectively, are comparatively displayed after background subtraction and normalization to unit.

The prompt difference in the sulfate concentration is reflected by the calculated ratio of the integrated area of the sulfate band at $979 \mathrm{~cm}^{-1}$ from the background subtracted and normalized spectra. The ratio value $\mathrm{R}=\mathrm{A}\left(\mathrm{SO}_{4}{ }^{2-}\right)_{\mathrm{Coj}_{-} 1,2} /$ A (water) was calculated in both cases and the ratio of their values $\mathrm{r}=$ $\mathrm{R}_{1} / \mathrm{R}_{2}=1.449$. Normal Raman scattering of sulfate solutions being linearly increased with concentration (Ishizaka et al 2013), the results prompted for the sulfate concentrations ratio of the two lakes (Fig. 2). 


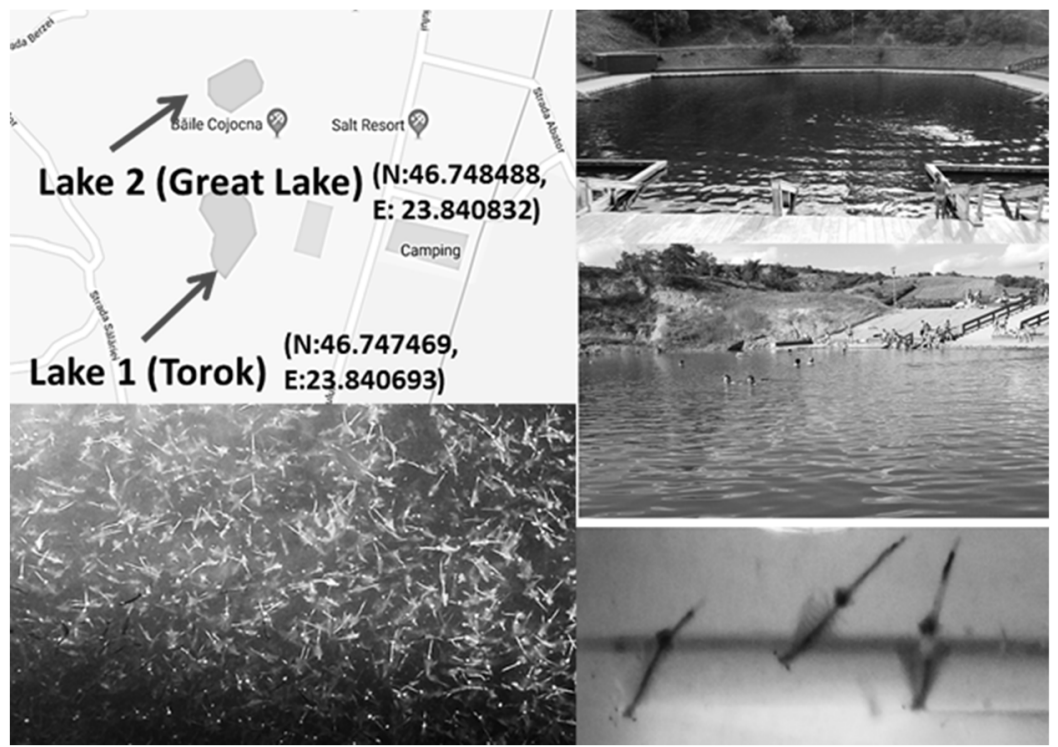

Fig. 1. Cojocna Lakes map and images (Lake 1 showing regular blueish aspect while Lake 2 appeared dark green during the Artemia salina bloom in August 2016.

Bottom image shows a snap shot of the Lake 2 surface revealing high density of crustaceans.

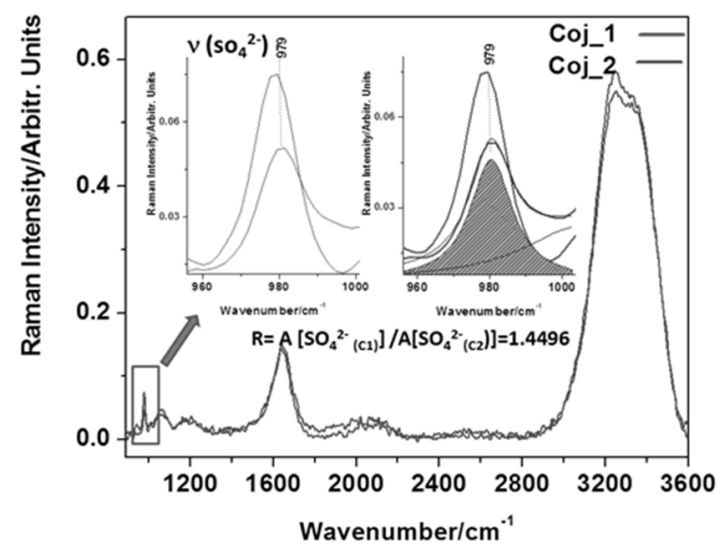

Fig. 2. FT-Raman spectra of the surface waters $(0.3 \mathrm{~m}$ depth) from Lake 1 and Lake 2, sampled in July 2016. The insertions show the detailed Raman band of sulfate with different intensity in the two lakes. The fitted area was used to calculate the sulfate ratio $R$ of the two lakes.

Water samples taken in August 2017 showed different feature. FT-Raman spectra of the raw water (Lake 1) showed an additional broaden band at $1528 \mathrm{~cm}^{-1}$, characteristic to carotenoids (Fig. 3), timely correlated with the Artemia species bloom in August 2017. Comparative to the water signal from July 2016 (Fig. 2), the band in Fig. 3 b suggests the presence of increased density of photosynthetic microorganisms bearing carotenoids. Thus, from raw data is can be concluded the increased phytoplankton density, making directly observable the increased carotenoids presence. Furthermore, analysis of the bottom vial water (bearing particulate matter and increasing amount of sediments, one could observe quite strong intensity of the carotenoids bands in the FT-Raman spectra of raw water. 


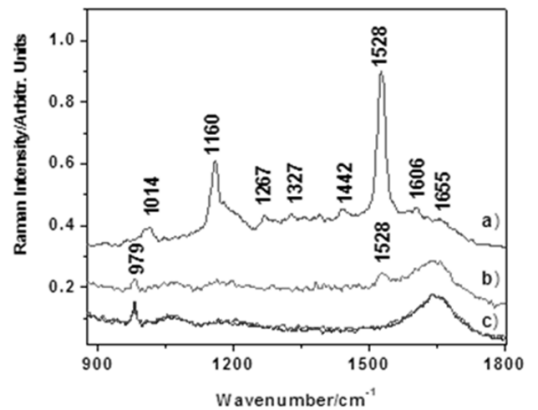

\subsection{Dispersive Raman spectra of the hypersaline waters}

Several typical Raman spectra of the freshly sampled raw waters (August, 2017) from Cojocna Lakes and excited with the $532 \mathrm{~nm}$ laser line are showed in the Fig. 4. Spectra were collected with the Renishaw system. A lower resolution Raman system (DeltaNU) revealed only strong fluorescence signal from the lakes samples, where the carotenoids trace were poorly discernible (not showed here). The raw signal collected in $5 \mathrm{~s}$ with $0.5 \mathrm{~cm}^{-1}$ resolution showed good reproducibility among samples and comprised strong fluorescence background superimposed with weak bands.

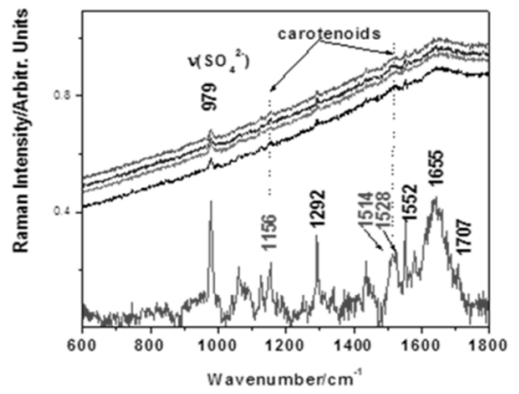

Fig.4. Raman spectra of raw waters collected from Cojocna Lakes in fall August 2017 and the corresponding processed signal, revealing detailed fingerprint of carotenoids, sulfate and other organic constituents. Excitation: $532 \mathrm{~nm}$.

Processing steps have been applied to extract relevant information from the raw data: spectra were background subtracted and normalized to unit. A detailed, processed spectrum is showed in the bottom of the Fig. 4 and highlights the well resolved bands. The detailed fingerprint spectral range from 600 to 1800 $\mathrm{cm}^{-1}$ showed in the Fig. 4 revealed the typical fingerprint of carotenoids with $\mathrm{C}=\mathrm{C}$ stretching mode of the polyene chain in the $1514-1528 \mathrm{~cm}^{-1}$ (suggesting multiple species) and the C-C stretching at $1156 \mathrm{~cm}^{-1}$, band which is less selective for the carotenoid molecular structure discrimination. Among the two lakes, similar calculations of the areas ratio of sulfate to water Raman bands resulted in Coj_1 (Torok Lake) showing 0.7978, while Coj_2 (Great Lake) 0.8923, respectively. 
Again, the sulfate level was found different, this time the ratio among lakes showed 0.737 times higher sulfate concentration for Lake 1 than Lake 2, both sampled in August 2017 respectively. The relative errors were calculated as 0.0014 $(0.14 \%)$ from three distinct measurements per sample. The sulfate ratio calculation has been accomplished according to the calculated ratio of the Raman band of sulfate at $979 \mathrm{~cm}^{-1}$ relative to water band at $1636 \mathrm{~cm}^{-1}$ from the background subtracted, normalized, averaged spectra. Furthermore, bands attributable to nitrate $\left(1056 \mathrm{~cm}^{-1}\right)$, carbonate $\left(1083 \mathrm{~cm}^{-1}\right)$, as well as bands characteristic to organic constituents (1655 $\mathrm{cm}^{-1}$ usually assigned to amide I in proteins), C-N stretching characteristic to proteins, carbonyl band at $1707 \mathrm{~cm}^{-1}$, other trace characteristics to polyunsaturated fatty acids, possible methane trace $\left(2917 \mathrm{~cm}^{-1}\right.$, spectra range not showed here), all these observations suggest rich and complex chemical composition of the lakes, which could be further addressed in detail, combining information from multiple Raman spectroscopy approaches, to Raman enhancing techniques. For now, raw hypersaline waters from balneary resorts could be easily tracked regarding possible chemical changes via Raman spectroscopy. Further results on water dried matter and single cell microorganisms inhabiting the balneary waters, using combined spectroscopic techniques will be addressed elsewhere.

\section{CONCLUSIONS}

We prospected the capability of the Raman spectroscopy techniques for raw waters analysis from hypersaline lakes of a balneary resort. We have shown that Raman spectra of salt waters promptly showed different signal for each lake, indicating different chemical composition. We found that the Lake 1 (Torok) showed 1.449 times higher sulfate concentration than Lake 2 in July 2016 and this value appeared changed one year later. In August 2017 the value was 0.737. Apparently, the sulfate fluctuation is correlated to the alternative variation in Artemia salina population in August in the two lakes, namely, the abundance is higher when sulfate concentration is lower. However, systematic monitoring, beyond this preliminary study will be more relevant in drawing firm conclusions on further possible correlations. Chemical changes associated with the presence of different plankton species and density, correspond to specific Resonance Raman scattering signal of water. Change of water signal during the Artemia sp. bloom in early August has been observed. Obviously, the natural inflow on the water in two lakes should similarly contribute to their trophic equilibrium. Carotenoids in raw waters were detectable both via dispersive Raman spectroscopy and FT-Raman and indicated multiple species and different spectral output of the two lakes. Concluding, Raman spectroscopy techniques showed great potential for chemical characterization and monitoring purpose of the hypersaline waters from balneotherapeutic resorts. 


\section{REFERENCES}

1. Alexe, M., Șerban, G., Baricz, A., Andrei, A.-S., Cristea A., Battes, K.P., Cîmpean, M., Momeu, L., Muntean, V., Porav, S.A., Banciu, H.L. (2017), Limnology and plankton diversity of salt lakes from Transylvanian Basin (Romania): A review, J. Limnol. DOI: 10.4081/jlimnol.2017.1657

2. Alinei, R., Ionica. A., Cheratoiu, C., Cicu, A., Gheorghita, D., Guzu, D., Falamas, R., Bucurenciu, C., Arimie, B., Morinescu, M., Oprean, L. (2006), Isolation of halophylic microorganisms in the saline lakes from Ocna Sibiului and analysis of red pigments production. Acta Univ. Cibiensis. E X(2), 21-33.

3. de Leeuw, A., Bukowski, K., Krijgsman, W., Kuiper, K. (2010), Age of the Badenian salinity crisis; impact of Miocene climate variability on the circumMediterranean region. Geology, 38(8), 715-718.

4. de Leeuw, A., Mandic, O., Krijgsman, W., Kuiper, Hrvatović, H. (2012), Paleomagetic and geochronologic constraints on the geodynamicsc evolution on the Central Dinarides Tectonophysics 530-531(2), 286-298.

5. Borowitzka, L.J. (1981), The microflora. Adaptations to life in extremely saline lakes, Hydrobiologia. 81, 33-46.

6. Borowitzka, M.A., Siva, C.J. (2007), The taxonomy of the genus Dunaliella (Chlorophyta, with emphasis on the marine and halophilic species. J. Appl. Phycol. 19: 567-590.

7. Carpa, R., Reti, K., Macalik, K., Török, E., Remizovschi, A., Székely, G. (2017), Influence of salt content on enzymatic activities and halophytes distribution in Cojocna zone, Romania. Studia UBB Biologia LXII (2), 21-32

8. Cintă Pinzaru S., Müller Cs, Tomšić S., Venter M. M, Cozar B. I,. Glamuzina B. (2015), New Sers feature of $\beta$-carotene: consequences for quantitative SERS analysis, J. Raman Spectr. 46, 597-604.

9. Cinta Pinzaru, S, Müller, Cs, Tomšić, S. Venter, M. M., Brezestean, I., Ljubimir, S., and Glamuzina, B. (2016), Live diatoms facing Ag nanoparticles: surface enhanced Raman scattering of bulk cylindrotheca closterium pennate diatoms and of the single cells, RSC Adv., 2016, 6, 42899-42910.

10. Clavero, E., Hernandez-Marine, M., Grimalt, J.O., Garcia-Pichel, F. (2000), Salinity tolerance of diatoms from thalassic hypersaline environments. J. Phycol. 36, 1021-1034.

11. Czellecz B, Gabor I, Ravasz L, Schiopu G, Szops H. (2017), Saline water resources in Cluj-Napoca surroundings. DOI: 10.17378/AWC2016_52, aerapa.conference.ubbcluj.ro/2016/52_Czellecz.htm; Available via license: CC BY 4.0.

12. Gheorghievici, L., Gheorghievici, Gh,, Tănase, I. (2015), The Phytoplankton Composition Features of Five Romanian Pelogenous Ecosystems. Environm. Engn. 14(5), 975-984.

13. Ishizaka, S., Yamauchi, K., Kitamura, N. (2013), In situ quantification of ammonium sulfate in single aerosol droplets by means of laser trapping and Raman spectroscopy. Anal. Sci. 29(12), 1223-1226.

14. Jehlička. J., Oren A. (2013), Raman spectroscopy in halophile research. Front. Microbiol. 4, 1-7. 
15. Keresztes, Z.G., Somogyi, B., Boros, E., Szekely, G., Bartha, C., Nagy, E., Dragos, B., Voros, L. (2010), Picoplankton in soda lakes of the Carpathian basin. Contrib. Bot. $X L V, 41-46$.

16. Keresztes, Z.S., Felföldi, T., Somogyi, B., Székely, G., Dragoş, N., Márialigeti, K., Bartha, Cs., Vörös, L. (2012), First record of picophytoplankton diversity in Central European hypersaline lakes, Extremophiles 16(5), 759-769.

17. Krezsek, Cs., Filipescu, S. (2005), Middle to late Miocene sequence stratigraphy of the Transylvanian Basin (Romania), Tectonophys. 410(1-4), 437-463.

18. Lewin, R.A., Krienitz, L., Goericke, R., Takeda, H., Hepperle, D. (2000), Picocystis salinarum gen. et sp. nov.(Chlorophyta) - a new picoplanktonic green alga. Phycologia, 39, 560-565

19. Marshall, C.P., Leuko, S., Coyle, C.M., Walter, M.R., Burns, B.P., Neilan, B.A. (2007), Carotenoid analysis of halophilic archaea by resonance Raman spectroscopy. Astrobiology 7(4), 631-643.

20. Muñoz-Iglesias, V., Bonales, L.J., Prieto-Ballesteros, O. (2013), pH and salinity evolution of Europa's brines: Raman spectroscopy study of fractional precipitation at 1 and 300 bar. Astrobiology 13(8), 693-702

21. Muntean, V., Crisan, R., Pasca, D., Kiss, S., Dragan-Bularda, M. (1996), Enzymological classification of salt lakes in Romania. Int. J. Salt Lake Res. 5, 3544.

22. Oren, A. (2014), The ecology of Dunaliella in high-salt environments. J. Biol. Res. - Thessalon. 21, 23

23. Roesler, C.S., Culbertson, C.W., Etheridge, S.M., Goericke, R., Kiene, R.P., Miller, L.O., Oremland, R.S. (2002), Distribution, production, and ecophysiology of Picocystis strain ML from Mono Lake, California.Limnol. Oceanogr. 47, 440452.

24. Singh, P., Baranwal, M., Reddy, S.M. (2016), Antioxidant and cytotoxic activity of carotenes produced by Dunaliella salina under stress. Pharm. Biol. 54(10), 22692275.

25. Teodoresco, E.C. (1905), Organisation et développement du Dunaliella, nouveau genre de Volvocacée-Polyblépharidée. Beih. Bot. Centralbl. 18, 215-232. 